\title{
Smoothing out the wrinkles
}

'My impression from what I have seen so far,' writes George Racz from London, 'is that you are holding up a mirror to the English language, so that we can see all the wrinkles in it - but I have not found advice on how to smooth them out.

'I am concerned with the lack of uniformity in English: Different spellings, pronunciations, constructions are heard and/or seen and there is noone [sic] who has the authority to say which is right, inquire or enquire, dispatch or despatch, different from or different to. . . I do not know a single French or German word which a schoolboy can spell or pronounce in more than one way with impunity. Such freedom exists only in English or Such freedom only exists in English. Until someone is authorised to rule on these matters the language will continue to lack uniformity and one day will become unteacheable [sic].'

There it is, in a nutshell, a theme in many of the letters that come to $E T$, and a particular theme among those correspondents - all of them older males living in or linked with England - who have announced that they are not renewing their subscriptions or at best have been giving $E T$ one more year to get it right. And getting it right appears to mean appointing ourselves as the arbiters at least of the standard language if not crusaders for the standardization of all 'deviant' forms of English wherever they are. The gist of the complaint is that $E T$ has not been set up as the new Académie Anglaise, and should have been so set up. While this is a relatively rare response, it does represent in a more extreme form the hope expressed by other - usually enthusiastic - readers that ET should offer guidance about a wide range of usage issues.

David Crystal and I have discussed the degree to which $E T$ should crusade for anything at all, well aware that if we do become unabashed crusaders for Plain English or Spelling Reform then that is that. The magazine will be typecast thereafter, and cease to be what we have perceived as important: a forum for all sorts of reporting and commenting upon the language, on both the wrinkles and on ways of smoothing them for those who wish to see them smoothed. To date we hope we have shown that anyone with a concise and well-constructed statement about any aspect of English today stands a good chance of having that statement published - to be read by thousands of people in some 50 countries around the world.

Is this enough? Are the comparative usage surveys, the airing of opinions about usage controversies, the comments on tenses and taboo language, and on language varieties (their similarities or differences) as much as one can reasonably hope or be expected to do, or is there more to a magazine about the English language than (1) describing the language in line with the latest linguistic knowledge about it, (b) providing a place for the interchange of reports, reviews, ideas and opinions, and (c) leaving it to readers to draw their own conclusions about their own usage? We would like to hear from interested readers on whether what we are doing offers enough help in difficult areas of usage, what might be done and of course constructive suggestions on how to do it. A cross-section of these responses will be published as a special report.

As we move towards the end of ET's second complete year it does however become easier to see where the magazine is going. In physical terms, it goes to publishers, journalists, authors, poets, educators, schools, colleges and universities, libraries and all kinds of individuals from Argentina to the United Arab Emirates. In the short period of its existence, the Post $\mathcal{E}$ Mail section has swelled from zero to five pages of letters (and more, when we count readers' input to other parts of each issue). This is a healthy sign, and many people have commented that they find the letters as intriguing as anything else in the magazine. However, space in a quarterly of 40-odd pages is limited, and I would urge potential correspondents to seek the most concise form for their letters so as to avoid any disappointment when a few paragraphs have to be left out in order to get the main points in.

A quarterly magazine has its own rhythms, one of which is the necessity of setting the material for the next issue as soon as the current issue goes out. This can mean that letters regarding an item in, say, ET6 won't get into ET7 and have to wait for ET8. At present we see no way round this delay - which is however less than most 'learned' publications. We can only hope that readers are perennially interested in the topics concerned, and in any case such topics tend to recur in new forms. Few issues in English are ever resolved at one blow, pace those who profoundly wish that they could be.

At one blow, however, in this issue David Crystal has taken on the nature and the statistics of literacy, Greta Little has surveyed the apostrophe, Robert Le Page and Ashton Gibson report on West Indian English, and both Margot Lawrence and Martyn Wakelin delve into the roots of modern English in Tudor and Jacobean times. Stephen Wade's concern is Anglo-Irish literature, while there is more on the 'plupluperfect' tense as well as items on Esperanto, Esperanglish, Ozperanto, AngloArabesques, 'might of' and 'must of', Manx, Usasians, Shakespeare, Pravda, Afrikaans, 'bowsers' and 'wowsers', Lucky Luke, Secs, Recs and Asdating - as well as the possible completion of the Oxford English Dictionary (for the moment at least), after a century of not quite smoothing out all the wrinkles.

Tom McArthur

Letters to the editor should be addressed to a branch of Cambridge University Press (for forwarding), or directly to:

Dr Tom McArthur

Editor, English Today

22-23 Ventress Farm Court

Cherry Hinton Road

CAMBRIDGE CB1 4HD

Fnoland 